\title{
Interpreting the new illness question in the UK census for health research on small areas
}

\author{
Stephen Martin, Trevor A Sheldon, Peter Smith
}

\begin{abstract}
Study objective-The study aimed to identify the various factors that seem to influence the average response to the new census question on limiting, long standing illness at the small area level, to assess the extent to which the new question adds to information already available in the census and elsewhere, and to discuss how useful the data are likely to be for those planning health and social services.

Design - This was a cross sectional analysis of the relationship between rates of limiting, long standing illness (standardised for age and sex) and a large number of indicators of health and socioeconomic status at the small area level.

Setting - The study used data relating to 4985 small areas covering the whole of England. The average population was about 10000.
\end{abstract}

Participants - The 1991 census of population was addressed to the entire population of England.

Main results - There are wide variations in the levels of self reported long standing illness between small areas, $70 \%$ of which are explained by demographic factors. Variation in age/sex standardised responses to the new census question at the small area level can largely be explained by census data on self reported disability among those of working age, standardised mortality ratio, and by indicators of socioeconomic circumstances relating to social class, ethnicity, and the elderly living alone. There does not seem to be a significant reporting bias due to unemployment.

Conclusions - Unlike the disability question in the census, the standardised, self reported long standing limiting illness ratio covers the entire population and it is not skewed towards men. Although the variable is a synthesis of the health and social determinants of perceived morbidity, it does not provide much information that was not already available. In addition, it is available every 10 years only and thus may be rather inaccurate as an indicator of relative need towards the end of the decade. Moreover, in future censuses, individuals' answers might be influenced by the knowledge that their responses will affect the volume of resources allocated to the area in which they live.

( $\mathcal{F}$ Epidemiol Community Health 1995;49:634-641)
The UK census of population is one of the most important sources of information for planning public services. Central government agencies, health and local authorities, and a variety of other public sector organisations use data on the demography and socioeconomic characteristics of local populations to estimate needs and allocate resources. Unfortunately, crude demographic data offer only an approximate indicator of the need for local services. Because of this various attempts have been made to develop indicators of need over and above demographic considerations. One of the most important requirements has been to develop a measure of morbidity as an index of the relative need for health care and social services. Hitherto, the principal indices of morbidity at the small area level have been the mortality data prepared by the Office of Population Censuses and Surveys (OPCS). However, there has been considerable debate about the limitations of mortality as a proxy for morbidity. ${ }^{1-3}$ In particular, it has been argued that while mortality may adequately reflect acute disease, it is not a suitable proxy for chronic illness. ${ }^{4}$

Since 1971, the general household survey (GHS) has included questions on long standing and acute illness as well as the use of hospital and general practitioner (GP) services. Analysis of the responses to these questions showed a high correlation between reported illness and the level of use of GP and hospital services. The GHS samples about 10000 households per year only, however, and does not offer sufficient data to explain variations in illness across small areas or for use in routine planning. A question on limiting, long term illness was therefore introduced in the 1991 census in the hope that it would yield useful information on the relative need for health care. ${ }^{6}$

This new health question sought information on the general prevalence of chronic morbidity rather than on specific disabilities or health states. The precise wording was as follows:

"Long term illness

Does the person have any long term illness, health problem or handicap which limits his/ her daily activities or the work he/she can do?

Include problems which are due to old age" (emphasis in original).

The respondent was invited to tick a box indicating either

"Yes, has a health problem which limits activities."

or

"Has no such health problem." 
The question applied to all individuals included in the census, and precensus tests showed that responses to this question were well correlated with GP consultations and with inpatient and outpatient visits to hospital. ${ }^{78}$ It was anticipated that responses to this question would provide ". . . a simple, but nationally comparable, indication of the need for health and personal social services for the long-term sick both nationally and within local and health authority areas". " However, when included in the OPCS omnibus survey, responses to the question proved a weak predictor of the utilisation of inpatient and GP services, although the addition of other sociodemographic variables considerably improved the explanatory power of the utilisation model. ${ }^{10}$

Moreover, the question was self reported, and may therefore be vulnerable to variations in reporting practice. It was claimed that although responses would not be completely reliable for identifying absolute totals, response bias would not vary from one geographical area to another. ${ }^{11}$ However, O'Donnell and Propper ${ }^{12}$ identify differences in reporting between social groups in response to general questions about morbidity, such as this census question. Unless the distribution of social groups is similar across all areas, reporting bias may cause problems in interpretation.

Before the inclusion of the question in the census, routine sources of information about health status at the small area level already existed. The census had included a question about long term sickness/disability among those of working age. This question asked about the person's economic activity in the week preceding the census, and one possible response was "unable to work because of long-term sickness or disability". In addition, the mortality data compiled by the OPCS can be disaggregated in relation to age, sex, and cause of death at the small area level to create a number of standardised mortality rates.

This report aims to examine the various factors that seem to influence the average response to the new census question at the small area level, to assess the extent to which the new question adds to information already available in the census and elsewhere, and to discuss how useful the data are likely to be for those planning health and social services.

The virtue of using a small area level of analysis rather than data on individuals is that it permits linkage with data on the social and economic characteristics of the areas in which individuals live and mortality data which are only reliably available at this level of aggregation. Data sets at this level are more likely to be available to health service planners.

Age/sex standardised responses to the new census question will be influenced by various factors. Firstly, we examine the impact of directly measured health circumstances, as indicated by mortality and self reported permanent sickness. Since both ill health and self reported ill health are likely to be socially influenced, however, these effects are explored using various socioeconomic variables. Our hy- pothesis is that responses to the new census question will be jointly determined by:

- Some "objective" measure of the individual's health state;

- His or her perception of what constitutes ill health; and

- His or her interpretation of the census question. ${ }^{13}$

\section{Methods}

We first examined the demographic and geographical distribution of morbidity as measured by the new census question. We reported rates of limiting, long term illness in relation to age and sex for 4985 small areas in England and compared these with alternative indicators of health care needs. We examined how much of the variation in limiting, long term illness could be explained by age and sex, and then constructed age/sex standardised illness ratios (SIRs) for the 4985 small areas.

We calculated the rates of limiting, long term illness for small areas per 1000 population in relation to age and sex, firstly for all residents, and then for residents in households. The latter category excludes residents in communal establishments (for example those in NHS and private hospitals, local authority and housing association homes, nursing and residential homes, children's homes, detention, defence and education establishments, hotels and boarding houses, and other establishments).

The units of analysis were "synthetic wards" covering the whole of England. These small areas were formed by amalgamating contiguous small electoral wards (with populations less than 5000) until a unit with a population of at least 5000 was obtained. The resulting 4985 small areas had an average population of about 9500 . The intention of this amalgamation procedure was to reduce the problem caused by small numbers of observations, particularly with regard to the mortality data. Further details about this amalgamation procedure can be found in Carr-Hill et al. ${ }^{14}$

In order to understand variations in illness between areas, it is essential to adjust for age and sex to capture differences in illness that result from the ward's age/sex profile. Direct and indirect SIRs were therefore calculated for all residents (including those living in institutions). The indices were multiplied by 100 so an SIR greater than this figure implied more (self reported) limiting, long term illness in a ward than could be explained solely by its age/ sex profile. Data were available by sex in 18 five year age bands, and the SIRs were calculated for five age groups (all ages, 0-64, 0-74, 65-74, and over 75) for each of 4985 synthetic wards. Indirect SIRs were also calculated for residents in households only.

In the same way, using the alternative census question, an indirectly standardised sickness/ disability ratio (SSR) was calculated for those of working age. In addition, the usual (indirectly) standardised mortality ratios (SMRs) were available for each ward aggregated for the three years 1990-92. 
Table 1 Rates of limiting, long term illness and long term sickness/disability, per 1000 population, by age and sex in England

\begin{tabular}{|c|c|c|c|c|c|c|}
\hline \multirow{3}{*}{$\begin{array}{l}\text { Age } \\
\text { group } \\
(y)\end{array}$} & \multicolumn{4}{|c|}{ Limiting, long standing illness } & \multirow{2}{*}{\multicolumn{2}{|c|}{$\begin{array}{l}\text { Long term } \\
\text { sickness/disability }\end{array}$}} \\
\hline & \multicolumn{2}{|c|}{ All residents } & \multicolumn{2}{|c|}{$\begin{array}{l}\text { Residents in } \\
\text { households }\end{array}$} & & \\
\hline & Male & Female & Male & Female & Male & Female \\
\hline $0-4$ & $21 \cdot 3$ & 16.9 & $21 \cdot 2$ & $16 \cdot 9$ & $\mathrm{n} / \mathrm{a}$ & $\mathrm{n} / \mathrm{a}$ \\
\hline $5-15$ & $27 \cdot 7$ & $22 \cdot 1$ & $27 \cdot 4$ & $21 \cdot 9$ & $\mathrm{n} / \mathrm{a}$ & $\mathrm{n} / \mathrm{a}$ \\
\hline $16-17$ & $28 \cdot 0$ & $26 \cdot 0$ & $27 \cdot 4$ & $25 \cdot 5$ & $2 \cdot 69$ & $2 \cdot 84$ \\
\hline $18-29$ & $38 \cdot 9$ & $34 \cdot 4$ & $36 \cdot 5$ & $33 \cdot 1$ & $14 \cdot 21$ & 12.07 \\
\hline $30-44$ & $60 \cdot 8$ & $55 \cdot 2$ & $57 \cdot 5$ & $53 \cdot 4$ & $27 \cdot 94$ & $23 \cdot 73$ \\
\hline $45-54$ & $116 \cdot 6$ & $116 \cdot 1$ & $113 \cdot 1$ & $114 \cdot 1$ & $60 \cdot 50$ & 55.92 \\
\hline $55-59$ & $207 \cdot 1$ & $187 \cdot 7$ & $204 \cdot 0$ & 185.9 & $120 \cdot 36$ & 89.05 \\
\hline $60-64$ & $299 \cdot 9$ & $225 \cdot 1$ & $295 \cdot 8$ & $221 \cdot 4$ & $180 \cdot 39$ & $\mathrm{n} / \mathrm{a}$ \\
\hline $65-74$ & $342 \cdot 8$ & $314 \cdot 0$ & $336 \cdot 0$ & $305 \cdot 8$ & $\mathrm{n} / \mathrm{a}$ & $\mathrm{n} / \mathrm{a}$ \\
\hline $75-84$ & $455 \cdot 7$ & $498 \cdot 2$ & $436 \cdot 4$ & $467 \cdot 0$ & $\mathrm{n} / \mathrm{a}$ & $\mathrm{n} / \mathrm{a}$ \\
\hline $85+$ & $626 \cdot 2$ & $722 \cdot 7$ & $571 \cdot 6$ & $642 \cdot 6$ & & $\mathrm{n} / \mathrm{a}$ \\
\hline All ages & $119 \cdot 5$ & $136 \cdot 2$ & $114 \cdot 8$ & $125 \cdot 8$ & $48 \cdot 23^{*}$ & $31 \cdot 27^{*}$ \\
\hline
\end{tabular}

Source: 1991 census.

* All those of working age. added to the model, yet contributed little to increasing its explanatory power. Thus, in the interests of economy, a cut off criterion was adopted in which no further variables were added to the model when the most recent addition had increased the adjusted $\mathrm{R}^{2}$ statistic by less than 0.005 .

A separate model was estimated for each of the following SIRs:

- All residents aged 0-74;

- All residents aged over 75;

- Residents in households of working age;

- Residents in households aged 0-74;

- Residents in households aged over 75 .

The models were estimated first with other directly measured health variables included, and then omitting health variables. The first approach seeks to isolate the incremental impact of social conditions on reported sickness, while the latter approach seeks to capture their total impact. be explained by directly measured health factors, we first examined the correlation between various SIRs, the comparable SMRs, and the SSR. In order to examine these associations further, the SIR for those aged under 75 was regressed, firstly against the corresponding SMR, then with SSR as the regressor, and finally with both variables as explanatory variables. In this and all subsequent regression models, natural logarithms were taken of all variables (so that a multiplicative model was employed).

A large number of additional variables, mainly drawn from the census, were constructed. In summary, these covered the following aspects of social and economic circumstances: housing tenure; housing amenities; car ownership; overcrowding; ethnic origin; elderly living alone; lone parents; educational attainment; migrants; unemployment; social class; and non-earning households.

Simple pairwise correlations between these socioeconomic variables and the SIRs were calculated. Models of SIR were then developed using multivariate regression analysis. Atkinson's added variable plot was used as a method for incorporating new variables. ${ }^{15} \mathrm{We}$ began with SIR as the dependent variable and SSR as the sole regressor. The correlation coefficients between the residuals from this regression and the socioeconomic variables were examined and the variable exhibiting the highest correlation was selected. This was regressed on the variable already in the model (SSR), and the residuals from this regression were entered as an additional explanatory variable. This procedure was repeated several times to identify further social variables that added new information to the model.

Where collinearity is present, Atkinson's approach has the advantage that the estimated coefficients on the previously included variables remain unchanged as additional variables are added to the model. The net impact of the additional variables can therefore be more easily identified. Because of the large number of observations, many of the socioeconomic variables proved statistically significant when

\section{Results}

Table 1 shows the rates of limiting, long standing illness in relation to age and sex. As was expected, the rate of long term illness increased with age and was lower for residents in households than for those in communal establishments - the latter category included nursing and residential homes.

Over all age and sex groups, the rate of limiting, long term illness per 1000 population was:

$128 \cdot 10$ for all residents;

120.45 for all residents in households;

520.42 for all residents in communal establishments;

691.56 for residents in medical care communal establishments;

117.01 for residents in non-medical care communal establishments.

These data confirmed that there was a particularly high rate of illness in communal establishments or, more precisely, in medical care communal establishments. The relatively small number of people in these establishments, however, meant that there was little difference between the rate for all residents and that for residents in households. Nevertheless, because medical care communal establishments are concentrated in certain locations, there are small areas (for example, along the Sussex coast) where the two rates differed appreciably. The potential difficulty of modelling this locational phenomenon encouraged us to maintain the distinction between all residents and those in households. However, models of the rate of illness in households will not be sensitive to what is going on in areas with a large number of medical care establishments. This should be borne in mind when interpreting the results.

Table 1 also shows the rate of long term sickness/disability for those of working age. Over the entire working population the rate was 40.06 people per 1000 . In absolute terms, the numbers were considerably smaller than 
Table 2 Rates of limiting, long term illness and permanent sickness, per 1000 population, by regional health authority

\begin{tabular}{|c|c|c|c|c|c|c|c|c|c|}
\hline \multirow[t]{3}{*}{ Health region } & \multicolumn{6}{|c|}{ Limiting, long standing illness } & \multirow{2}{*}{\multicolumn{3}{|c|}{ Long term sickness/disability }} \\
\hline & \multicolumn{3}{|c|}{ All residents } & \multicolumn{3}{|c|}{ Residents in households } & & & \\
\hline & Mean & $(S D)$ & Rank & Mean & $(S D)$ & Rank & Mean & $(S D)$ & Rank \\
\hline $\begin{array}{l}\text { Northern } \\
\text { Yorkshire } \\
\text { Trent } \\
\text { East Anglia } \\
\text { North West Thames } \\
\text { North East Thames } \\
\text { South East Thames } \\
\text { South West Thames } \\
\text { Wessex } \\
\text { Oxford } \\
\text { South West } \\
\text { West Midlands } \\
\text { Mersey } \\
\text { North West }\end{array}$ & $\begin{array}{l}159 \cdot 2 \\
133 \cdot 6 \\
137 \cdot 8 \\
116 \cdot 6 \\
104 \cdot 5 \\
122 \cdot 4 \\
125 \cdot 5 \\
107 \cdot 2 \\
118 \cdot 4 \\
96 \cdot 7 \\
128 \cdot 6 \\
127 \cdot 8 \\
145 \cdot 9 \\
151 \cdot 8\end{array}$ & $\begin{array}{l}(35 \cdot 1) \\
(25 \cdot 7) \\
(32 \cdot 8) \\
(25 \cdot 6) \\
(21 \cdot 8) \\
(29 \cdot 4) \\
(30 \cdot 5) \\
(29 \cdot 7) \\
(31 \cdot 3) \\
(23 \cdot 4) \\
(28 \cdot 3) \\
(26 \cdot 1) \\
(33 \cdot 6) \\
(30 \cdot 9)\end{array}$ & $\begin{array}{r}14 \\
10 \\
11 \\
4 \\
2 \\
6 \\
7 \\
3 \\
5 \\
1 \\
9 \\
8 \\
12 \\
13\end{array}$ & $\begin{array}{r}151 \cdot 3 \\
124 \cdot 8 \\
130 \cdot 7 \\
109 \cdot 9 \\
99 \cdot 1 \\
117 \cdot 0 \\
116 \cdot 8 \\
97 \cdot 8 \\
109 \cdot 4 \\
90 \cdot 4 \\
118 \cdot 1 \\
120 \cdot 8 \\
137 \cdot 8 \\
142 \cdot 9\end{array}$ & $\begin{array}{l}(34 \cdot 8) \\
(24 \cdot 9) \\
(32 \cdot 3) \\
(23 \cdot 0) \\
(19 \cdot 3) \\
(27 \cdot 4) \\
(25 \cdot 8) \\
(23 \cdot 3) \\
(26 \cdot 5) \\
(20 \cdot 9) \\
(23 \cdot 8) \\
(26 \cdot 0) \\
(32 \cdot 8) \\
(29 \cdot 8)\end{array}$ & $\begin{array}{r}14 \\
10 \\
11 \\
5 \\
3 \\
7 \\
6 \\
2 \\
4 \\
1 \\
8 \\
9 \\
12 \\
13\end{array}$ & $\begin{array}{l}68 \cdot 7 \\
41 \cdot 1 \\
44 \cdot 8 \\
29 \cdot 5 \\
28 \cdot 1 \\
36 \cdot 7 \\
33 \cdot 2 \\
23 \cdot 1 \\
27 \cdot 7 \\
22 \cdot 4 \\
33 \cdot 1 \\
40 \cdot 1 \\
63 \cdot 0 \\
62 \cdot 1\end{array}$ & $\begin{array}{l}(29 \cdot 0) \\
(16 \cdot 0) \\
(21 \cdot 1) \\
(12 \cdot 2) \\
(15 \cdot 1) \\
(15 \cdot 8) \\
(12 \cdot 7) \\
(11 \cdot 9) \\
(11 \cdot 9) \\
(12 \cdot 2) \\
(11 \cdot 9) \\
(17 \cdot 0) \\
(29 \cdot 2) \\
(24 \cdot 9)\end{array}$ & $\begin{array}{r}14 \\
10 \\
11 \\
5 \\
4 \\
8 \\
7 \\
2 \\
3 \\
1 \\
6 \\
9 \\
13 \\
12\end{array}$ \\
\hline All regions & $127 \cdot 2$ & $(33 \cdot 6)$ & & $119 \cdot 4$ & $(31 \cdot 5)$ & & $39 \cdot 6$ & $(22 \cdot 9)$ & \\
\hline
\end{tabular}

Table 3 Descriptive statistics for assorted standardised illness ratios (SIR) and sickness/disability ratios (SSR) for 4985 synthetic wards

\begin{tabular}{|c|c|c|c|c|}
\hline Variable & Mean & $(S D)$ & Minimum & Maximum \\
\hline $\begin{array}{l}\text { Indirect SIRs } \\
\text { All ages } \\
\text { Age } 0-64 \mathrm{y} \\
\text { Age } 0-74 \mathrm{y} \\
\text { Age } 65-74 \mathrm{y} \\
\text { Age } 75+\mathrm{y}\end{array}$ & $\begin{array}{r}\text { esidents) } \\
99 \cdot 42 \\
99 \cdot 27 \\
99 \cdot 01 \\
99 \cdot 31 \\
100.01\end{array}$ & $\begin{array}{l}(23.94) \\
(35.54) \\
(29.98) \\
(20.10) \\
(10.81)\end{array}$ & $\begin{array}{l}48 \cdot 29 \\
35 \cdot 90 \\
41 \cdot 57 \\
48 \cdot 18 \\
60 \cdot 33\end{array}$ & $\begin{array}{l}217 \cdot 88 \\
285 \cdot 44 \\
246 \cdot 75 \\
189 \cdot 01 \\
137 \cdot 82\end{array}$ \\
\hline $\begin{array}{l}\text { Indirect SIRs } \\
\text { All ages } \\
\text { Age } 0-64 \text { y } \\
\text { Age } 0-74 \text { y } \\
\text { Age } 65-74 \text { y } \\
\text { Age } 75+\mathrm{y}\end{array}$ & $\begin{array}{c}\text { ehold resid } \\
99.4 \\
99 \cdot 17 \\
98.96 \\
99.31 \\
100.57\end{array}$ & $\begin{array}{r}\text { ents only) } \\
(25 \cdot 24) \\
(36 \cdot 15) \\
(30 \cdot 57) \\
(20 \cdot 49) \\
(11 \cdot 29)\end{array}$ & $\begin{array}{l}49 \cdot 90 \\
34 \cdot 06 \\
40 \cdot 33 \\
45 \cdot 14 \\
58 \cdot 10\end{array}$ & $\begin{array}{l}226 \cdot 3 \\
292 \cdot 85 \\
252 \cdot 59 \\
191 \cdot 46 \\
146 \cdot 01\end{array}$ \\
\hline \multicolumn{4}{|c|}{ Indirect SIRs (household residents of working age) } & $300 \cdot 83$ \\
\hline $\begin{array}{l}\text { Indirect SSR } \\
\text { All }\end{array}$ & $\begin{array}{l}\text { sse of wo } \\
99 \cdot 29\end{array}$ & $\begin{array}{r}\text { king age) } \\
(57 \cdot 68)\end{array}$ & $12 \cdot 48$ & $462 \cdot 30$ \\
\hline
\end{tabular}

those reporting limiting, long standing illness, particularly in the younger age groups. The rate of increase with age, however, was greater than that for limiting illness.

Table 2 reports the mean rates of limiting, long term illness and long term sickness/disability for all synthetic wards in each of the 14 former regional health authorities (RHAs) in England. The northern regions (Mersey, northern, and north west) had the worst rates of both illness and sickness/disability. Details of individual wards with particularly high or low values of SIR can be found elsewhere. ${ }^{16}$ Again, there was a considerable difference in the absolute values of the two variables. The ranking of the RHAs in terms of each variable, however, were very similar. For example, in all three

Table 4 Correlation coefficients between various indirectly standardised illness ratios

\begin{tabular}{llllllll}
\hline Age (y) & All ages & $\begin{array}{l}\text { Age } \\
0-64 y\end{array}$ & $\begin{array}{l}\text { Age } \\
0-74 y\end{array}$ & $\begin{array}{l}\text { Age } \\
65-74 y\end{array}$ & $\begin{array}{l}\text { Age } \\
75+y\end{array}$ & $\begin{array}{l}H R^{*} \\
\text { Age } \\
0.74 y\end{array}$ & $\begin{array}{l}H R^{*} \\
\text { Age } \\
75+y\end{array}$ \\
\hline All ages & 1.000 & 0.983 & 0.994 & 0.918 & 0.724 & 0.977 & 0.744 \\
$0-64$ & & 1.000 & 0.994 & 0.859 & 0.620 & 0.975 & 0.668 \\
$0-74$ & & & 1.000 & 0.908 & 0.659 & 0.983 & 0.705 \\
$65-74$ & & & & 1.000 & 0.748 & 0.902 & 0.781 \\
$75+$ & & & & 1.000 & 0.637 & 0.846 \\
HR $^{*}$ & & & & & & 1.000 & 0.730 \\
$0-74$ & & & & & & & 1.000 \\
HR $^{*}$ & & & & & & & \\
$75+$ & & & & & & &
\end{tabular}

${ }^{*} \mathrm{HR}=$ household residents only. cases the Oxford and northern regions had the lowest and highest rates of illness/sickness respectively. Moreover, the rankings were similar (but not identical) to those derived from other sources, such as the health and lifestyle survey. ${ }^{17}$

To ascertain the importance of demography, the rate of limiting, long term illness for all residents in each small area was regressed on the proportions in each age/sex group. Each ward was weighted by its share of the total population. The resulting ordinary least squares regression indicated that differences in demographic characteristics explained $70 \cdot 2 \%$ of the variation in (self reported) limiting, long term illness between small areas in England.

Descriptive statistics of the SIR and SSR are shown in table 3 . There was very little difference between the direct and indirectly standardised illness rates, so results for indirectly standardised ratios only are shown. The results for all residents and those only in households were broadly similar. There was substantial variation in the SIRs across synthetic wards: for example, the all ages indirect SIR varied from under 49 to over 217. This suggests that at least one ward had an illness rate that was less than half that of the national rate, while another had a rate more than double that across the whole country.

The older the age group covered by the SIR, the smaller the variation across wards (as was seen in the lower SDs and small ranges for the older age groups in table 3). This probably reflects the fact that, as populations age, a smaller proportion of the variation in morbidity is due to variations in socioeconomic factors. Finally, the SSR exhibited a far greater degree of variation across the wards than did any of the SIRs. While the SSR varied between 12 and 462, the SIR for those of working age ranged from 33 to 300 .

Correlation coefficients between the different indirect SIRs are reported in table 4, and confirmed that many of the indicators were very highly correlated. In particular, the high correlations between the SIRs for household residents and for all residents should be noted. In addition, because of the high degree of association between indirectly standardised SIRs and their directly standardised coun- 
Table 5 Mean standardised illness ratios for those aged 0-74y and those over $75 y$, and standardised sickness ratio and standardised mortality ratio (SMR) for all wards in relation to health region

\begin{tabular}{|c|c|c|c|c|c|c|c|c|c|c|c|c|}
\hline \multirow[t]{3}{*}{ Health region } & \multicolumn{6}{|c|}{ Limiting, long standing illness } & \multirow{2}{*}{\multicolumn{3}{|c|}{$\begin{array}{l}\text { Long term sickness/ } \\
\text { disability }\end{array}$}} & \multirow{2}{*}{\multicolumn{3}{|c|}{$\begin{array}{l}S M R \\
\text { Aged 0-74 }\end{array}$}} \\
\hline & \multicolumn{3}{|c|}{ Aged 0-74 } & \multicolumn{3}{|c|}{ Aged $75+$} & & & & & & \\
\hline & Mean & $(S D)$ & Rank & Mean & $(S D)$ & Rank & Mean & $(S D)$ & Rank & Mean & $(S D)$ & Rank \\
\hline Northern & $129 \cdot 6$ & $(33 \cdot 5)$ & 14 & $109 \cdot 0$ & $(10 \cdot 8)$ & 14 & $167 \cdot 1$ & $(70 \cdot 7)$ & 14 & $119 \cdot 5$ & $(25 \cdot 6)$ & 14 \\
\hline Yorkshire & $103 \cdot 1$ & $(24 \cdot 7)$ & 10 & $103 \cdot 8$ & $(8 \cdot 5)$ & 10 & 102.5 & $(42 \cdot 5)$ & 10 & $104 \cdot 7$ & $(20.0)$ & 11 \\
\hline Trent & $108 \cdot 6$ & $(30.5)$ & 11 & $104 \cdot 7$ & $(11 \cdot 4)$ & 12 & $111 \cdot 3$ & $(54 \cdot 0)$ & 11 & $101 \cdot 4$ & $(19 \cdot 3)$ & 9 \\
\hline East Anglia & 84.9 & $(16 \cdot 7)$ & 4 & 94.5 & $(7 \cdot 8)$ & 3 & $72 \cdot 7$ & $(30 \cdot 1)$ & 4 & 85.0 & $(15 \cdot 2)$ & 1 \\
\hline North West Thames & $84 \cdot 9$ & $(23 \cdot 1)$ & 5 & $94 \cdot 5$ & $(9 \cdot 5)$ & 4 & $74 \cdot 1$ & $(41 \cdot 0)$ & 5 & $94 \cdot 4$ & $(21 \cdot 8)$ & 6 \\
\hline North East Thames & $100 \cdot 2$ & $(26 \cdot 5)$ & 8 & $99 \cdot 5$ & $(8 \cdot 7)$ & 8 & $95 \cdot 9$ & $(42 \cdot 8)$ & 8 & $100 \cdot 4$ & $(21 \cdot 2)$ & 8 \\
\hline South East Thames & $94 \cdot 2$ & $(22 \cdot 0)$ & 7 & $96 \cdot 3$ & $(8 \cdot 6)$ & 7 & $85 \cdot 1$ & $(35 \cdot 2)$ & 7 & $98 \cdot 0$ & $(22 \cdot 4)$ & 7 \\
\hline South West Thames & $76 \cdot 1$ & $(18 \cdot 8)$ & 1 & $92 \cdot 3$ & $(9 \cdot 3)$ & 1 & $59 \cdot 1$ & $(31 \cdot 8)$ & 2 & $86 \cdot 7$ & $(17 \cdot 9)$ & 2 \\
\hline Wessex & $83 \cdot 2$ & $(18 \cdot 0)$ & 3 & $94 \cdot 0$ & $(8 \cdot 4)$ & 2 & $68 \cdot 0$ & $(29 \cdot 8)$ & 3 & $87 \cdot 1$ & $(16 \cdot 0)$ & 3 \\
\hline Oxford & $77 \cdot 8$ & $(18 \cdot 8)$ & 2 & $95 \cdot 6$ & $(8 \cdot 6)$ & 5 & $58 \cdot 4$ & $(32 \cdot 1)$ & 1 & $89 \cdot 1$ & $(17 \cdot 8)$ & 5 \\
\hline South West & 89.9 & $(18 \cdot 2)$ & 6 & $95 \cdot 9$ & $(8 \cdot 6)$ & 6 & $79 \cdot 7$ & $(29 \cdot 4)$ & 6 & $88 \cdot 4$ & $(16 \cdot 0)$ & 4 \\
\hline West Midlands & $101 \cdot 6$ & $(25 \cdot 5)$ & 9 & $103 \cdot 6$ & $(9 \cdot 7)$ & 9 & $99 \cdot 5$ & $(44 \cdot 0)$ & 9 & $102 \cdot 1$ & $(20 \cdot 5)$ & 10 \\
\hline Mersey & $121 \cdot 3$ & $(35 \cdot 5)$ & 12 & $104 \cdot 6$ & $(9 \cdot 7)$ & 11 & $156 \cdot 0$ & $(74 \cdot 7)$ & 12 & $112 \cdot 8$ & $(25.9)$ & 12 \\
\hline North West & $123 \cdot 8$ & $(30 \cdot 2)$ & 13 & $107 \cdot 9$ & $(8 \cdot 7)$ & 13 & $156 \cdot 1$ & $(64 \cdot 3)$ & 13 & $116 \cdot 8$ & $(24 \cdot 6)$ & 13 \\
\hline All regions & $99 \cdot 0$ & $(30 \cdot 0)$ & & $100 \cdot 0$ & $(10 \cdot 8)$ & & $99 \cdot 3$ & $(57 \cdot 7)$ & & $99 \cdot 4$ & $(25 \cdot 2)$ & $25 \cdot 2$ \\
\hline
\end{tabular}

Rank $-1=$ lowest standardised illness ratio, $14=$ highest one.

terparts, our subsequent analysis focused on the indirectly standardised rates to be consistent with SMRs, which are only routinely available in indirect form.

Table 5 shows how the SIR (all residents), SSR, and SMR vary between RHAs. Again, the northern regions had the worst rates of illness, sickness/disability, and mortality. As anticipated, there was far less variation between the regional SIRs for the older age group. In terms of ranking, however, the RHAs were in broadly similar positions for both age bands. In both cases, wards in south west Thames region had the lowest average SIR - almost $25 \%$ below the national average - while the average SIR was greatest in the northern region - almost $30 \%$ above the national average. The regional rankings were also very similar for the under $75 \mathrm{~s}$ SIR and the SSR, although once again the latter displayed far more variation than the former.

Tables 6 to 10 present the results of the analysis of the factors associated with variations in the SIRs across small areas. Table 6 shows the correlation between SIRs and selected health status variables. There was very high correlation $(0.96)$ between the all ages SIR and the SSR (which is restricted to those of working age). There was also a high correlation $(0.81)$ between the SIR for those aged under 75 and the corresponding SMR, confirming the good performance of mortality as a proxy for variations in morbidity in this age group.

Table 7 shows that directly measured health factors explain much of the variation in the

Table 6 Correlation coefficients between various indirectly standardised illness ratios (SIR) and the standardised sickness/disability ratio (SSR) and selected standardised mortality ratios (SMR)

\begin{tabular}{lllllll}
\hline & $\begin{array}{l}\text { SIR all } \\
\text { ages }\end{array}$ & $\begin{array}{l}\text { SIR } \\
0-74 y\end{array}$ & $\begin{array}{l}\text { SIR } \\
75+y\end{array}$ & $\begin{array}{l}\text { SIR } H R^{*} \\
0-74 y\end{array}$ & $\begin{array}{l}\text { SIR } H R^{*} \\
75+y\end{array}$ & $\begin{array}{l}\text { SIR } H R^{*} \\
\text { working age }\end{array}$ \\
\hline SSR & 0.959 & 0.970 & 0.616 & 0.940 & 0.642 & 0.944 \\
$\begin{array}{l}\text { SMR } \\
\text { all ages }\end{array}$ & 0.683 & 0.654 & 0.628 & 0.621 & 0.460 & 0.612 \\
$\begin{array}{l}\text { SMR } \\
\text { 0-74y }\end{array}$ & 0.805 & 0.807 & 0.559 & 0.791 & 0.565 & 0.784 \\
$\begin{array}{l}\text { SMR } \\
75+y\end{array}$ & 0.365 & 0.322 & 0.503 & 0.284 & 0.237 & 0.274 \\
\hline
\end{tabular}

${ }^{*} \mathrm{HR}=$ household residents only.
Table 7 Regressions (standard errors) of standardised illness ratios of those under age 75 years on mortality $(S M R)$ and sickness/disability (SSR) ratios

\begin{tabular}{lccc}
\hline & Model 1 & Model 2 & Model 3 \\
\hline Constant & -0.2384 & 2.2651 & 1.7562 \\
& $(0.0478)$ & $(0.0081)$ & $(0.0224)$ \\
SMR ages 0-74 y & 1.0484 & & 0.1636 \\
& $-(0.0104)$ & 0.5147 & $(0.0068)$ \\
SSR & & $(0.0018)$ & $(0.0028)$ \\
& & 0.943 & 0.949 \\
\hline
\end{tabular}

under 75 SIR. In model 1 , the SMR for those aged under 75 explained over $67 \%$ of the variation in the SIR, while the SSR explained over $94 \%$ of this variation (model 2). When the SMR was added to the model with the SSR (model 3), there was only a marginal, albeit statistically significant, increase in explanatory power.

As was noted above, illness, whether "objectively" measured or self assessed, may be socially influenced. The correlation coefficients between various SIRs and some of the socioeconomic variables are reported in table 8 . There were strong positive associations between the SIR and the proportion of residents without a car, the proportion of dependants in single carer households, and the rate of unemployment. The strongest correlate of the all age SIR was the rate of unemployment $(r=$ $0 \cdot 823$ ). The correlation with the proportion of dependants in no carer households was noticeably lower $(0.56)$, and may reflect that people capable of living without a carer may have a lower level of dependence than those living with a carer.

In building multiple regression models to explain the SIR, very similar results were obtained irrespective of which age group was used, and irrespective of whether all residents or only residents in households were included. In the interests of brevity, therefore, table 9 only reports models for the SIR of residents in households aged under 75 .

Model 1 was the result derived from regressing the SIR on the SSR and other socioeconomic variables. Model 2 was similar but in this instance the SSR was replaced by the 
Table 8 Correlation coefficients between various indirectly standardised illness ratios (SIRs) and selected socioeconomic variables

\begin{tabular}{lrrrrrr}
\hline $\begin{array}{l}\text { Socioeconomic } \\
\text { variables }\end{array}$ & $\begin{array}{l}\text { SIR } \\
\text { all ages }\end{array}$ & \multicolumn{1}{c}{$\begin{array}{l}\text { SIR } \\
0-74 y\end{array}$} & $\begin{array}{l}\text { SIR } \\
75+y\end{array}$ & $\begin{array}{l}\text { SIR } H^{*} \\
\text { working } \\
\text { age }\end{array}$ & $\begin{array}{l}\text { SIR } H R^{*} \\
\text { O-74y }\end{array}$ & $\begin{array}{l}\text { SIR } H R^{*} \\
75+y\end{array}$ \\
\hline Owner-occupier & -0.535 & -0.547 & -0.237 & -0.610 & -0.559 & -0.339 \\
No car & 0.819 & 0.833 & 0.445 & 0.823 & 0.844 & 0.547 \\
Overcrowding & 0.615 & 0.638 & 0.275 & 0.639 & 0.651 & 0.397 \\
Black & 0.235 & 0.247 & 0.041 & 0.249 & 0.254 & 0.123 \\
Old alone & 0.525 & 0.521 & 0.371 & 0.499 & 0.524 & 0.429 \\
One carer & 0.805 & 0.821 & 0.413 & 0.826 & 0.831 & 0.489 \\
No carer & 0.557 & 0.558 & 0.324 & 0.525 & 0.552 & 0.341 \\
Students & -0.499 & -0.509 & -0.374 & -0.499 & -0.528 & -0.468 \\
Migrants & -0.477 & -0.468 & -0.405 & -0.465 & -0.493 & -0.479 \\
Unemployed & 0.823 & 0.837 & 0.448 & 0.862 & 0.850 & 0.547 \\
\hline
\end{tabular}

Key to socioeconomic variables: Owner-occupier = proportion of residents in owner-occupation No car = proportion of residents with no car; Overcrowding = proportion in households with crowded accommodation; Black = proportion of residents in black ethnic groups; Old alone $=$ proportion of those aged $75+$ living alone; One carer $=$ proportion of dependent in single carer households; No carer = proportion of dependent in no carer households; Students = proportion of 17 year olds that are students; Migrants=proportion of residents moving from outside the local authority district in previous year; Unemployed = proportion of economically active that is unemployed.

${ }^{*} \mathrm{HR}=$ household residents only.

Table 9 Regressions (standard errors) of the standardised illness ratio for residents in households aged under 75 using Atkinson's added variable approach

\begin{tabular}{lccc}
\hline Variable & Model 1 & Model 2 & Model 3 \\
\hline SSR & 0.5088 & & 0.5088 \\
& $(0.894)$ & & $(0.894)$ \\
SMR ages 0-74 & & 1.0458 & 0.1866 \\
Non-manual & -0.1463 & $(0.647)$ & $(0.008)$ \\
& $(0.025)$ & & -0.2170 \\
1-Black & -0.4411 & & $-0.0055)$ \\
& $(0.005)$ & & $(0.0055)$ \\
Old alone & 0.1657 & 0.1917 & \\
One carer & $(0.004)$ & $(0.005)$ & \\
1-Indian & & 0.5313 & \\
Movers & & $(0.147)$ & \\
Kids no earner & & -0.3253 & \\
& & $0.012)$ & -0.0316 \\
Adjusted $\mathrm{R}^{2}$ & & $(0.0127)$ & $(0.002)$ \\
& & & 0.0657 \\
\end{tabular}

SSR = standardised sickness ratio (for those of working age); Non-manual $=$ proportion of persons in households with head
in class 1 or $2 ; 1-$-Black $=$ proportion of residents not in black in class 1 or $2 ; 1-B l a c k=$ proportion of residents not in black
ethnic groups; Old alone = proportion of those aged over 75 ethnic groups; Old alone = proportion of those aged over 75
living alone; One carer = proportion of dependents in single carer households; 1 -Indian =1-proportion of residents in Indian, Pakistani, and Bangladeshi ethnic groups; Movers = proportion of residents moving from outside local authority area in the last year; Kids no earner = proportion of children in non-earning families.

Table 10 Modelling the socioeconomic determinants of the standardised illness ratio for residents in households aged under 75 using Atkinson's added variable approach

\begin{tabular}{lrrrl}
\hline Variable & Coefficient & Beta coefficient & Adjusted $R^{2}$ & $\begin{array}{l}\text { Change in } \\
\text { adjusted } R^{2}\end{array}$ \\
\hline Unemployed & 0.4991 & 0.8539 & 0.7291 & 0.7291 \\
Manual & 0.3466 & 0.2953 & 0.8163 & 0.0872 \\
No carer & 0.1364 & 0.1427 & 0.8367 & 0.0204 \\
Private rented & -0.0477 & -0.1128 & 0.8494 & 0.0127 \\
Old alone & 0.1915 & 0.0648 & 0.8536 & 0.0042 \\
\hline
\end{tabular}

Unemployed = proportion of economically active that are unemployed; Manual=proportion of economically active residents in manual class; No carer = proportion of dependents in no carer households; Private rented = proportion of residents in privately rented accommodation; Old alone $=$ proportion of those aged over 75 living alone

All coefficients have a $p$ value $<0.0001$.

SMR. Finally, model 3 included both the SSR and SMR. Together, the SSR and SMR explained $90 \%$ of the variation between wards of the SIR for residents in households aged under 75 and, as model 3 shows, four additional social variables added a further $3 \cdot 5 \%$ to the adjusted $\mathrm{R}^{2}$ statistic.

Two variables were found to have a significant negative relationship with the SIR over and above the SSR and SMR. This implied that areas with a higher proportion of household heads in non-manual social classes and a larger proportion of residents moving from outside the district in the last year had a lower SIR, holding all other factors constant. On the other hand, the proportion of residents who reported themselves as being in a black ethnic group and the proportion of children in non-earning families were positively associated with the SIR.

The results in table 9 show the extent to which other health indicators explain variation in self reported, limiting, long standing illness. It is interesting to consider the extent to which it is possible to explain this variation using purely (exogenous) socioeconomic variables. The regression was repeated without use of health related variables (table 10 ).

The model explained $85 \%$ of the variation in the SIR and all of the variables had plausible interpretations. The unemployment rate was the single most important variable which alone explained $73 \%$ of the variation in the SIR, while the four other variables explained a further $12 \%$. The manual variable could be interpreted as a further indicator of low income. The significance of the no carer variable suggested, quite sensibly, that a dependent who is living on their own is more likely to experience a given condition as a limiting, long term illness than someone who is living with a carer, who, presumably, is able to help them with their daily life. The negative sign on the variable measuring the proportion of residents living in privately rented accommodation was at first rather surprising. However, this might be indicating areas with a relatively high proportion of students and thus the inverse relationship with the SIR is to be expected. A similar model emerged when the dependent variable was the SIR for those aged over 75 , although much less (about $50 \%$ ) of the variation in the dependent variable could be explained, for reasons discussed earlier.

In a regression, there is an implication that causation runs from the explanatory variables on the right hand side of the equation to the dependent variable on the left hand side. In the present context, this may suggest that unemployment "causes" illness. Clearly, it is also possible that illness may lead to unemployment, or that high unemployment in an area may cause an increase in the propensity to self report illness. ${ }^{18}$ This may occur, for example, if respondents believed that census returns might be made available to administrators of welfare benefits, and thus may have an effect on benefit eligibility.

To investigate such possibilities, we first examined the correlation between the SIR and unemployment for various age groups, and between the SIR and three other indicators of poverty (table 11). Although there was evidence that the correlation between the SIR and unemployment increased with age, there was also a similar pattern in the correlations between the SIR and the three other indicators of poverty.

Following the argument set out above, one might expect the change in correlations with age to be greater in the higher unemployment 
Table 11 Correlation between the standardised illness ratio (SIR) for various age groups and four indicators of deprivation

\begin{tabular}{|c|c|c|c|c|}
\hline \multirow[t]{2}{*}{ Age (y) } & \multicolumn{4}{|l|}{ SIR } \\
\hline & $\begin{array}{l}\text { Un- } \\
\text { employed }\end{array}$ & No car & $\begin{array}{l}\text { Owner- } \\
\text { occupied }\end{array}$ & $\begin{array}{l}\text { Over- } \\
\text { crowding }\end{array}$ \\
\hline $\begin{array}{l}16-17 \\
18-29 \\
30-44 \\
45-54 \\
55-59 \\
60-64 \\
65-74 \\
75-84 \\
85+\end{array}$ & $\begin{array}{l}0.380 \\
0.707 \\
0.869 \\
0.871 \\
0.800 \\
0.735 \\
0.708 \\
0.566 \\
0.249\end{array}$ & $\begin{array}{l}0.371 \\
0.661 \\
0.859 \\
0 \cdot 865 \\
0.799 \\
0.739 \\
0.716 \\
0.577 \\
0.242\end{array}$ & $\begin{array}{l}-0.279 \\
-0.504 \\
-0.614 \\
-0.591 \\
-0.505 \\
-0.440 \\
-0.438 \\
-0.354 \\
-0.142\end{array}$ & $\begin{array}{l}0.311 \\
0.493 \\
0.680 \\
0.698 \\
0.611 \\
0.534 \\
0.522 \\
0 \cdot 416 \\
0 \cdot 149\end{array}$ \\
\hline
\end{tabular}

Unemployed = proportion of economically active that are unemployed; No car = proportion of residents in households with no car; Owner-occupied = proportion of residents in owneroccupied accommodation; Overcrowding = proportion of residents in crowded accommodation.

areas. The above analysis was therefore repeated with the synthetic wards divided into three groups of equal size, reflecting low, medium, and high levels of unemployment. There was a higher level of correlation in the high unemployment wards. For example the correlation between unemployment and the SIR in the age group 45-54 was 0.725 in high unemployment wards and only 0.303 in those wards in the lowest tertile. However, the change in correlation with age was not noticeably different.

\section{Discussion}

The desire for an improved predictor of the need for health and social services at the small area level prompted the introduction of a question about limiting, long term illness in the 1991 census. The proportions of people who reported such a problem in relation to age and sex, and to health region have been presented. These are in broad agreement with variations in self reported health states identified in the general household survey and the health and lifestyle survey. ${ }^{19}$ In addition, these figures have been compared with similar data for those reporting long term sickness/disability - information which was already collected routinely in the census.

Although the variation in long term sickness/ disability is greater than in the comparable rate of long standing illness, the two variables are highly correlated. Differences in the age/sex profile account for $70 \%$ of the variation in the rate of illness across small areas, and age/sex standardised illness and sickness rates are also highly correlated $(r=0.97)$.

People's reporting of limiting, long standing illness is likely to depend on some objective level of illness and their perception or experience of their health state. Clearly, the latter might be influenced by the social environment, which might ease or exacerbate the experience of directly measured health factors. For example, someone living with two carers may find their (pure health) condition less restrictive than someone who is dependent on a single carer, and so may be less predisposed to reporting the illness as limiting.
The analysis cannot, however, disentangle these two components of variation in the SIR. The census question probably reflects the interaction of both these factors. This does not necessarily diminish the usefulness of the question, as for many purposes it may be more important to estimate the perceived need for health care than any objective measure of health status. Nevertheless, researchers have described some evidence of reporting differences between different social groups which may, for many purposes, reduce the usefulness of these responses as an indicator of relative need. ${ }^{12}$ It is also reported that values for self reported illness for small areas in Wales are systematically higher than wards with similar social characteristics in England (Professor Brian Jarman, personal communication). The validity of the results may also be reduced by the degree of non-response to the census in $1991 .^{20}$

Almost $90 \%$ of the variation in the SIR could be explained by responses to an existing census question and this figure increased to $92.8 \%$ with the addition of three further socioeconomic variables and to $93.5 \%$ with the addition of the SMR. The regression results indicated that, although two areas might have identical health needs, as indicated by the SSR and SMR, the economically better off area, as measured, in particular, by the proportion of persons in households whose head was in a non-manual class, was likely to have a lower SIR. People in this ward might have experienced their health condition as less limiting, perhaps because they had access to other resources which eased the impact of their health condition. The selection of the variable measuring the proportion of residents in black ethnic groups suggested that, holding all other factors constant, those in African and Caribbean ethnic groups also reported higher levels of limiting, long standing illness.

Although $90 \%$ of the variation in the SIR could be explained by responses to the existing census question on sickness/disability, there was, nevertheless, a further $10 \%$ which the SSR could not explain. Moreover, the SIR had two distinct advantages over the SSR. Firstly, it covered the entire population rather than just those of working age. This might be of importance where large sections of the population are retired (for example, along the Sussex coast). Secondly, the SIR was not skewed towards men as is the measure of permanent sickness. Irrespective of the age band chosen, the SMR will also be biased towards males because men die younger than women and, as has been noted above, mortality may not be an appropriate proxy for chronic illness. Therefore, the SIR may well assist the allocation of health care resources at the small area level. Indeed, it is noteworthy that the SIR contributed useful information in a model of hospital inpatient utilisation over and above both the SMR and SSR. ${ }^{21}$ The extent to which the extra cost of including this question in the census was justified, however, given the rather marginal contribution evident from this analysis, is not clear. 


\section{Conclusions}

Identifying the health care needs of small areas is clearly of central importance in the allocation of health care resources, not least given the increased importance of general practitioner (GP) fundholding. The new census question is likely to be of considerable interest in this process. Previous work has suggested that a simple question seeking self assessment of health status predicts the use of GP services and hospital inpatient care better than the limiting, long term illness question. ${ }^{7}$ The SIR refers to a wider population than the SSR, however, and it is not biased towards men as are both the SMR and SSR. Our analysis suggests that the new census question contains some information which is not also explained by SSR and SMR, but not much.

As with any variable derived from the census, there is the problem that such information is only available every 10 years. The relevance of the SIR compared with (say) the SMR and local unemployment statistics might therefore decline as the decade progresses. Moreover, it is also possible that individuals' answers to the census question will be influenced by the knowledge that their responses will affect the volume of resources allocated to the area in which they live. This casts doubt on the ability of policy makers to use responses to this question in subsequent censuses.

While the responses to the question represent a synthesis of health and social determinants of perceived morbidity, it is not clear the extent to which it may serve as a useful planning tool at the small area level. Health service planners should therefore be cautious of its use and not assume that it provides the single measure of need that many have sought.

This work arose from a study of the determinants of health care need in small areas commissioned by the UK Department of Health. Thanks are due to many participants in that study, in particular Keith Derbyshire and Peter Dick at the NHS
Executive, and to George Davey Smith for detailed comments on an earlier draft of this paper. Much of the data preparation on which the study relied was carried out by our colleague Geoff Hardman.

1 Brennan ME, Clare PH. The relationship between mortality and two indicators of morbidity. $\mathcal{F}$ Epidemiol Community Health 1980;34:134-8.

2 Mays N, Bevan G. Resource allocation in the health service London: Bedford Square Press, 1987

3 Carr-Hill RA. Health status, resource allocation and socioeconomic conditions. Interim report of the needs research study for Wolverhampton Borough Council and District Health Authority. York: Centre for Health Economics Occasional Paper, University of York, 1987.

4 Palmer SR. The use of mortality data in resource allocation. In: Brotherston J, ed. Morbidity and its relationship to resource allocation. Cardiff: Welsh Office, 1978:25-39.

allocation. Cardiff: Welsh Office, 1978:25-39.
5 Whitehead F. How the 1991 census should improve govWhitehead F. How the 1991 census should improve

6 Pearce D, Thomas F. The 1989 census test. Population Trends 1990;61:24-30.

7 Benzeval M, Judge K. The 1991 census health question. Discussion paper 4. London: King;s Fund Institute, 1993.

8 Dale A. Fieldwork and data processing. In: Dale A, Marsh $\mathrm{C}$, eds. The 1991 census user's guide. London: HMSO, 1993:84-110.

9 Dale A. The content of the 1991 census: change and continuity. In: Dale A, Marsh C, eds. The 1991 census user's guide. London: HMSO, 1993: 16-51.

10 Benzeval $M$, Judge $K$. The determinants of hospital utilization: implications for resource allocation in England. ization: implications for resource
Health Economics 1994;3:105-16.

11 Whitehead F. How the 1991 census should improve government statistics. Population Trends 1988;53:20.

12 O'Donnell O, Propper C. Equity and the distribution of UK NHS resources. Fournal of Health Economics 1991;10: $1-19$

13 Foster K, Wilmot A, Dobbs J. General household survey. Series GHS 19. London: HMSO, 1990.

14 Carr-Hill RA, Hardman G, Martin S, Peacock S, Sheldon TA, Smith P. A formula for distributing NHS revenues based on small area use of hospital beds. Occasional Paper, Centre for Health Economics. York: University of York, 1994

15 Atkinson AC. Plots, transformations and regression. Oxford. Oxford University Press, 1985:282.

16 Charlton J, Wallace $M$, White I. Long-term illness: results from the 1991 census. Population Trends 1994;75:18-25.

17 Mays N, Chinn S, Ho KM. Interregional variations in measures of health from the Health and Lifestyle Survey measures of health from the Health and Lifestyle Survey and their relation with indicators of health care need in

18 Bartley M. Unemployment and ill health: understanding the relationship. $\mathcal{F}$ Epidemiol Community Health 1994;48: 333-7.

19 Yuen P, Machin D, Balarajan R. Inequalities in health: socioeconomic differences in self-reported morbidity. Pub lic Health 1990;104:65-71.

20 Raleigh VS, Balarajan R. Public health and the 1991 census. BMF 1994;309:287-8.

21 Smith P, Sheldon TA, Carr-Hill RA, Martin S, Peacock S, Hardman $G$. Allocating resources to health authorities: results and policy implications of small area analysis of the use of inpatient services. BMF 1994;309:1050-4. 